\title{
Novel therapeutics in myeloproliferative neoplasms
}

\author{
Sangeetha Venugopal ${ }^{1}$ and John Mascarenhas ${ }^{2^{*}}$ (1)
}

\begin{abstract}
Hyperactive signaling of the Janus-Associated Kinase/Signal Transducers and Activators of Transcription (JAK/STAT) pathway is central to the pathogenesis of Philadelphia-chromosome-negative myeloproliferative neoplasms (MPN), i.e., polycythemia vera (PV), essential thrombocythemia (ET), and primary myelofibrosis (PMF) which are characterized by inherent biological and clinical heterogeneity. Patients with MPNs suffer from substantial symptom burden and curtailed longevity due to thrombohemorrhagic complications or progression to myelofibrosis or acute myeloid leukemia. Therefore, the management strategies focus on thrombosis risk mitigation in PV/ET, alleviation of symptom burden and improvement in cytopenias and red blood cell transfusion requirements, and disease course alteration in PMF. The United States Food and Drug Administration's (USFDA) approval of two JAK inhibitors (ruxolitinib, fedratinib) has transformed the therapeutic landscape of MPNs in assuaging the need for frequent therapeutic phlebotomy (PV) and reduction in spleen and symptom burden (PV and PMF). Despite improving biological understanding of these complex clonal hematopoietic stem/progenitor cell neoplasms, none of the currently available therapies appear to modify the proclivity of the disease per se, thereby remaining an urgent unmet clinical need and an ongoing area of intense clinical investigation. This review will highlight the evolving targeted therapeutic agents that are in early-and late-stage MPN clinical development.
\end{abstract}

Keywords: MF, ET, PV, JAK-STAT, CALR, Ruxolitinib, Fedratinib, Pacritinib, Imetelstat, CALR vaccine

\section{Introduction}

Polycythemia vera (PV), essential thrombocythemia (ET), and primary myelofibrosis (PMF) are clonal myeloproliferative neoplasms (MPN) with distinct hematological and clinicopathologic features that can be viewed as a disease spectrum [1]. Approximately $90 \%$ of patients with MPNs harbor mutations involving the JAK2, CALR, or $M P L$ genes (phenotypic drivers in MPN), resulting in hyperactivation of the Janus-Associated Kinase/Signal Transducers and Activators of Transcription (JAK/ STAT) signaling pathway [2-4]. Additionally, they may harbor mutations in the epigenetic modifiers (DNMT3A,

\footnotetext{
*Correspondence: john.mascarenhas@mssm.edu

${ }^{2}$ Division of Hematology/Oncology, Tisch Cancer Institute, Icahn School of Medicine at Mount Sinai, One Gustave L Levy Place, Box 1079, New York, NY 10029, USA

Full list of author information is available at the end of the article
}

TET2, ASXL1, IDH1/2, EZH2), RNA splicing (SRSF2, $U 2 A F 1$ ), tumor suppressor (TP53) genes that co-operate with each other, and the driver mutations to bestow a more advanced disease phenotype [5]. While patients with PMF suffer from debilitating constitutional symptoms, progressive splenomegaly and cytopenias, PV and ET patients experience microvascular symptoms (headaches, erythromelalgia, Raynaud syndrome) and grievous life-threatening thromboses (arterial and venous) [6, 7]. In general, patients with MPN are at an increased risk of developing thrombosis compared to the general population (PV $>\mathrm{ET}>\mathrm{PMF}$ ) [8] and may progress to acute myeloid leukemia (PMF $>$ PV $>$ ET) [9]. Therefore, prevention of thrombosis and disease progression form the twopronged approach in the treatment strategy of MPNs. While the current prognostic models in PV and ET are predicated on the clinical and hematological parameters original author(s) and the source, provide a link to the Creative Commons licence, and indicate if changes were made. The images or other third party material in this article are included in the article's Creative Commons licence, unless indicated otherwise in a credit line to the material. If material is not included in the article's Creative Commons licence and your intended use is not permitted by statutory regulation or exceeds the permitted use, you will need to obtain permission directly from the copyright holder. To view a copy of this licence, visit http://creativecommons.org/licenses/by/4.0/. The Creative Commons Public Domain Dedication waiver (http://creativeco mmons.org/publicdomain/zero/1.0/) applies to the data made available in this article, unless otherwise stated in a credit line to the data. 
that predict the risk of recurrent thrombosis $[10,11]$, the integration of molecular and clinical data in PMF has allowed for more refined risk stratification and early evaluation for hematopoietic cell transplantation (HCT) [12], which remains the only curative treatment modality.

\section{Agents in clinical development in PV and ET}

Age ( $<60$ vs. $>60$ years) and the history of thrombosis form the basis of the risk-adapted approach informing the management decisions in PV and ET as thrombosis is the leading cause of preventable death in these MPNs [11, 13]. Patients younger than 60 years of age with no history of thrombosis are categorized as "low risk" and managed conservatively with therapeutic phlebotomy to maintain a hematocrit less than $45 \%$ in PV [14]. In both PV and ET, these low-risk patients are counseled to optimize cardiovascular risk factors (smoking, blood pressure, obesity) and prescribed low-dose aspirin for thrombosis prevention except in $J A K 2$ wild-type ET patients who are deemed as very low risk and maintained on observation only [15]. Cytoreductive therapy is reserved for those patients with "high-risk" features in both ET and PV and low-risk PV patients suffering from uncontrolled symptoms, symptomatic splenomegaly, and intolerance to therapeutic phlebotomy. While hydroxyurea $(\mathrm{HU})$ is the initial drug of choice [16], [17] pegylated interferon- $\alpha$ (IFN $\alpha$ ) is preferred in younger patients desiring offspring as $\mathrm{HU}$ is a potential teratogen $[18,19]$ and ruxolitinib, a JAK1/2 inhibitor for those PV patients who are intolerant or resistant to $\mathrm{HU}[20,21]$.

Although low-risk PV patients are managed with therapeutic phlebotomy and aspirin, they still experience higher than normal rates of thrombosis compared to the general population [8] as they may not have a well-controlled hematocrit $(<45 \%)$ between visits that may predispose them to poor outcomes secondary to hyperviscosity. Additionally, therapeutic phlebotomy leads to iron deficiency-related symptoms that may exacerbate/mimic PV-related symptoms. In this regard, hepcidin mimetics are being evaluated in PV as an alternative to therapeutic phlebotomy as hepcidin regulates iron metabolism, limits intestinal iron absorption, and restricts erythropoiesis. Preclinical studies of minihepcidin in murine models of PV have shown that prolonged administration curbs the availability of iron to erythroid precursors, thereby impeding erythropoiesis, resulting in the normalization of hematocrit [22]. PTG300, a selfinjectable hepcidin mimetic administered weekly, is currently being evaluated as a "medical phlebotomy agent" in a phase II study in PV patients requiring frequent therapeutic phlebotomy (NCT04057040).

Given the inherent risk of thrombosis in PV regardless of the current risk stratification, the move to initiate cytoreductive therapy to mitigate the risk of thrombosis in low-risk PV patients is gaining momentum. IFNo may have disease-modifying activity in MPNs as evidenced by preclinical studies; several small phase 2 studies have shown that IFNa treatment can induce molecular and cytogenetic responses in treated MPN patients, although the results vary according to the series. While some investigators have reported that patients harboring TET2 co-mutations do not respond as well to IFN $\alpha$ as those harboring wildtype, others have reported that patients with low JAK2 V617F variant allele frequency (VAF) are more likely to achieve complete hematological response with IFN $\alpha$ treatment than those with higher VAF at baseline [23-26]. Nevertheless, IFN $\alpha$ appears to induce hematological, molecular, and cytogenetic responses [27] and the clinical benefit of IFN $\alpha$ appears to be optimal when employed earlier in the disease course. In this context, the LOW PV trial is evaluating Ropeginterferon alfa-2b (Ropeg) compared to therapeutic phlebotomy in a phase II randomized clinical trial in low-risk PV patients. Ropeg is a monopegylated interferon that overcomes the shortcomings of IFNa (administered weekly), allowing for less frequent dosing (administered every two weeks) and improved patient tolerability ensuring long-term patient compliance [28]. Maintaining hematocrit $\leq 45 \%$ for 12 months in the absence of progressive disease is the primary composite endpoint of the LOW PV trial. The recently presented preplanned interim analysis shows that $84 \%$ of patients on the ropeg arm achieved the primary composite endpoint (60\% in the phlebotomy arm; $\mathrm{OR}=3.5,95 \% \mathrm{CI} 1.3-10.4, p=0.008)$ with a lower number of required therapeutic phlebotomy after one year of treatment ( $43 \%$ vs. $57 \% ; p=0.024)$. Ropeg was well tolerated with no significant difference in adverse events (AE) between both treatment arms. This trial has stopped enrollment in view of the resounding efficacy, and followup will continue for 2 years per protocol [29]. The final results of this trial may have practice-changing implications in patients with low-risk PV.

Previously, the Myeloproliferative Disorders Research Consortium (MPD-RC) 112 study and MPD-RC 111 study have highlighted the activity of IFN $\alpha$ in treatmentnaïve and HU-resistant/refractory ET/PV patients, respectively $[26,30]$. Most recently, phase III randomized controlled trials, PROUD-PV and its extension study CONTINUATION-PV, evaluated ropeg against $\mathrm{HU}$ in patients with PV. PROUD-PV was powered to establish the non-inferiority of ropeg against $\mathrm{HU}$ with a composite primary endpoint of complete hematological response (CHR) and resolution of splenomegaly at 12 months; $\mathrm{CHR}$ and symptomatic improvement were the coprimary endpoints in the CONTINUATION-PV study. At a median follow-up of 182 weeks in the ropeg arm, 21\% 
(28\% in HU arm at a median follow-up of 164 weeks) and $53 \%$ of patients ( $38 \%$ in $\mathrm{HU}$ arm, $p=0.044$ ) met the primary endpoints in PROUD-PV and CONTINUATIONPV study, respectively. CHR without the spleen criterion in the ropeg arm was met in $43 \%$ (46\% in HU, $p=0.63$ at 12 months) and $71 \%$ (51\% in HU, $p=0.012$ at 36 months) in the PROUD-PV and CONTINUATION-PV, respectively. Liver enzyme abnormalities were the most frequently reported grade $3 / 4$ adverse events in the ropeg arm and expected myelosuppression in the $\mathrm{HU}$ arm with comparable rates between the groups. Neuropsychiatric manifestations in the ropeg arm were rare [31]. Given these encouraging results, Ropeg is currently approved in Europe as a first-line agent for the treatment of PV in the absence of symptomatic splenomegaly and is under review for FDA approval in the USA.

Givinostat, a histone-deacetylase (HDAC) inhibitor has demonstrated preclinical activity in selective targeting of the JAK2 V617F clone by inhibiting the downstream signaling [32]. Subsequently, several studies have shown that givinostat is clinically active either as monotherapy or in combination with $\mathrm{HU}[33,34]$. Most recently, givinostat was evaluated in a dose-finding/proof of concept study in patients with PV. Givinostat exhibited on-target activity, and $100 \mathrm{mg}$ twice daily was deemed the recommended phase 2 dose (RP2D). In part B, proof of concept phase, the ORR rate was $80.6 \%$ at the end of three cycles and $50 \%$ of patients reported symptomatic improvement (pruritus, headache) with givinostat treatment. Almost all patients experienced grade $1 / 2$ treatment-related adverse event (TEAE) [diarrhea-51\%; thrombocytopenia-45\%; increased serum creatinine-37\%]. Based on these results, a registration trial of givinostat in PV patients is underway [35].

The P53-MDM2 axis is a novel therapeutic target in MPNs. MDM2 negatively regulates $\mathrm{p} 53$, promotes its degradation as well as inhibits $p 53$ transcription. Preclinical studies have shown that MDM2 is upregulated in JAK2 V617F-positive MPN hematopoietic progenitor cells, resulting in low p53 RNA levels that has led to the evaluation of MDM2 inhibitors in MPNs [36]. A recently published proof of concept study of Idasanutlin, an oral MDM2 inhibitor, in the second-line setting in patients with high-risk PV/ET demonstrated an overall response rate (ORR) of $58 \%(7 / 12)$ and a durable response (16.8 months) with monotherapy. Idasanutlin was well tolerated with no dose-limiting toxicities; low-grade gastrointestinal toxicity (diarrhea/nausea in $80 \%$ ) was common but manageable with a scheduled antiemetic regimen. Collectively, idasanutlin demonstrated safety and on-target clinical activity in JAK inhibitor-naïve, HU/IFN-resistant, or intolerant PV/ET patients. A global phase II trial in HU refractory PV is underway [37].
(NCT03287245) Following suit, KRT232, a potent small molecule oral MDM2 inhibitor, is being evaluated as a second-line agent in phlebotomy-dependent PV patients (NCT03669965).

Lysine-specific demethylase 1 (LSD1) is an epigenetic enzyme that maintains steady-state hematopoiesis and LSD1 inhibition-abrogated erythropoiesis, granulopoiesis, and thrombopoiesis in a reversible fashion. Additionally, LSD1 is found to be overexpressed in MPNs [38]. IMG7289 (bomedemstat), an LSD1 inhibitor, reduced splenomegaly, normalized blood counts, and prolonged survival in the Jak2 V617F murine model [39], which has led to the clinical evaluation of bomedemstat as a second-line agent in PV and ET (NCT04254978) (NCT04262141).

Furthermore, the recent understanding of the mechanistic basis of CALR mutated MPN has revealed several potential novel therapeutic targets, especially in harnessing host immunity. CALR mutations generate a novel positively charged $C$ terminus in the CALR protein, which could be exploited as a potential shared neoantigen, as the physical interaction between CALR and MPL is essential for $C A L R$-induced myeloproliferation [40, 41]. Additionally, studies have shown that CALR is immunogenic and immune escape occurs in patients with $C A L R$-mutated MPN [42]. In this regard, CALRspecific CD4+T-cell clone, which demonstrated specific cytotoxicity against autologous $C A L R$-mutant cells, has been generated [43], and these results have formed the basis of a phase 1 CALR exon 9 peptide vaccine in CALRmutated MPNs. (NCT03566446) Most recently, Bozkus et al. demonstrated that a subset of patients with CALRmutated MPN exhibits specific T-cell responses against the CALR C-terminus that is completely abrogated by the expression of PD-1 or CTLA4. Ex vivo treatment with an anti-PD-1 antibody restored mutant CALR-specific T-cell responses in the peripheral blood mononuclear cells of CALR-mutated MPN patients [44]. Clinical evaluation of a vaccine-based approach in combination with a PD-1 inhibitor is underway.

\section{Agents in clinical development in MF (Fig. 1)}

Ruxolitinib, a JAK1/JAK2 inhibitor (2011) [45] and fedratinib, a JAK2/FLT3 inhibitor (2019) [46] are approved in the USA for MF patients with splenomegaly and/ or constitutional symptoms regardless of the presence of mutated $J A K 2$. Although long-term follow-up studies have validated the sustained benefit of ruxolitinib in MF patients in terms of improvement in splenomegaly, symptom burden, and quality of life with an increase in overall survival (OS), a subset of patients are intolerant or refractory to JAK inhibitor therapy. While the median OS in ruxolitinib-treated patients is 60 months, 




the median OS post ruxolitinib discontinuation drops significantly (14 months) [47, 48]. Furthermore, clonal evolution or the finding of platelets $<100 \times 10^{9} / \mathrm{L}$ at the time of ruxolitinib discontinuation was found to be associated with particularly poor prognosis in patients with MF. Additionally, Kuykendall et al. evaluated the clinical outcomes and salvage treatment options in patients who received and discontinued ruxolitinib. In 64 evaluable patients, new cytopenias (anemia-33\%; thrombocytopenia-11\%) were the most common reasons for an impediment to ruxolitinib continuation after a median treatment time of 3.8 months. Of note, $26 \%$ of patients responded to salvage treatment options leading to better outcomes than those who did not receive additional therapy, suggesting that responses were salvageable in some patients even after ruxolitinib discontinuation. However, these responses were rare, representing an area of unmet clinical need in ruxolitinib pretreated patients with MF [49]. Therefore, there is a constant drive to improve upon the existing treatment options in patients with MF. Currently, many novel therapeutic agents are in clinical development in the front-line setting (monotherapy), "Add on" with ruxolitinib as a complementary therapeutic strategy, second-line setting, or treatment directed at mitigation of cytopenias (Fig. 2).

\section{Front-line setting}

Pacritinib is a multikinase inhibitor of JAK2, FLT3, IRAK1, and CSF1R, with less myelosuppressive effect noted in the early-phase trials and further evidenced by the anemia response [25\% achieved transfusion independence (TI)] and platelet improvement (35\% increase in mean platelet count noted in those with a baseline platelet count lower than $50 \times 10^{9} / \mathrm{L}$ ) in the PERSIST-1 


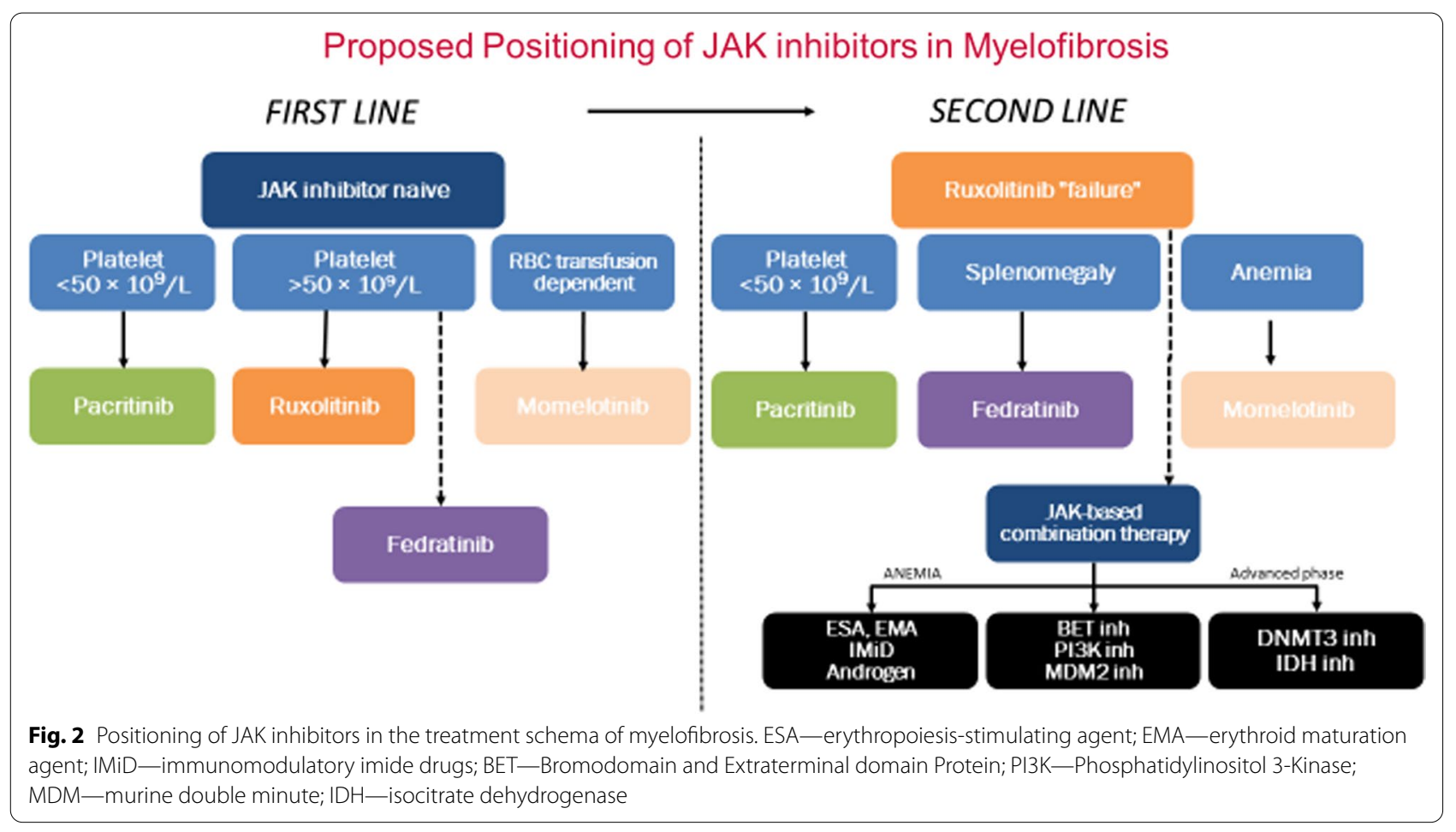

randomized controlled trial in JAK inhibitor naïve patients with MF [50]. PERSIST-2, a randomized controlled trial, evaluated pacritinib in MF patients with either disease or therapy-related (ruxolitinib) thrombocytopenia (platelets $<100 \times 10^{9} / \mathrm{L}$ ), and they were randomized to two doses of pacritinib (200 mg BID or $400 \mathrm{mg}$ once daily) or BAT (best available therapy), which could include ruxolitinib as well. Eighteen percent of patients enrolled on the pacritinib arms achieved $\geq 35 \%$ spleen volume reduction (SVR35\%) compared with 3\% on the BAT arm $(p=0.001)$, and these improvements were more noticeable in the pacritinib $200 \mathrm{mg}$ BID arm [ $\geq 35 \%$ SVR: $22 \%$ vs. $3 \% ; p=0.001 ; \geq 50 \%$ reduction in myelofibrosis-related total symptom score (TSS50): $32 \%$ vs. $14 \% ; p=0.01]$. Grade 3 or more thrombocytopenia, cardiac AEs, and therapy discontinuation were less frequent in the twice-daily arm [51]. Pacritinib development was interrupted due to the full clinical hold placed by the FDA in February 2016 due to safety concerns (increased hemorrhagic risk and mortality), which prompted an independent review that deemed mortality rates were not different between the study arms. Recently presented phase II PAC203 (NCT03165734) dose-finding (100 mg daily, $100 \mathrm{mg}$ twice daily, and $200 \mathrm{mg}$ twice daily) study evaluated pacritinib with preplanned built-in safety protocols for mitigating cardiac and hemorrhagic risk (concomitant anticoagulant/antiplatelet and QTprolonging agents were contraindicated). Pacritinib was well tolerated, and $17 \%$ of patients with severe thrombocytopenia $\left(<50 \times 10^{9} / \mathrm{L}\right)$ attained spleen responses in the $200 \mathrm{mg}$ BID cohort [52]. Given that thrombocytopenia (especially platelet count $<50 \times 10^{9} / \mathrm{L}$ ) is a poor prognostic factor in patients with MF and ruxolitinib is only approved for those with a minimum platelet count of $50 \times 10^{9} / \mathrm{L}$, pacritinib can potentially bridge this chasm and offer a viable therapeutic option for this challenging population subset. The PACIFICA phase III registration trial will evaluate the safety and efficacy of $200 \mathrm{mg}$ BID of pacritinib compared to the physician's choice (lowdose ruxolitinib, corticosteroids, hydroxyurea, or danazol), in patients with MF and severe thrombocytopenia $\left(<50 \times 10^{9} / \mathrm{L}\right)$ and less than 12 weeks of prior JAK inhibitor therapy [53] (NCT03165734).

\section{Ruxolitinib "Add-on" strategies}

Itacitinib is a selective JAK1 inhibitor being evaluated in MF under the premise that selective JAK1 inhibition will abrogate proinflammatory signaling without affecting the JAK2-mediated hematopoiesis. A phase II open-label study evaluated the safety and efficacy of three dose levels [100 $(n=10)$ or $200 \mathrm{mg}$ BID [45], $600 \mathrm{mg}$ QD [32]] of itacitinib in MF patients with TSS50 at week 12 as the primary endpoint. In total, $35.7 \%$ and $35.5 \%$ achieved the primary endpoint in the $200 \mathrm{mg}$ BID and $600 \mathrm{mg}$ QD as compared to $20 \%$ in the $100 \mathrm{mg}$ BID cohort. Modest SVR was observed in the higher dose cohorts. Notably, 
$53.8 \%$ experienced $\mathrm{a} \geq 50 \%$ reduction in the number of red blood cell units transfused, and fatigue was the most common TEAE [54]. Itacitinib is currently being evaluated in two cohorts with one cohort in combination with ruxolitinib and the other in JAK inhibitor failure/intolerance in patients with MF (NCT03144687).

Masarova et al. investigated the sequential combination of ruxolitinib with azacitidine, a hypomethylating agent, preceded by an initial run-in phase with ruxolitinib monotherapy. In total, $72 \%$ (33/46) of patients achieved an objective response per International Working Group for Myelofibrosis Research and Treatment (IWG-MRT) criteria with a median time to response of 1.8 months, and most responses occurred on ruxolitinib monotherapy. In total, $57 \%$ of patients experienced $\geq$ grade 1 improvement in bone marrow fibrosis (BMF). Of note, 20\% (3/15) of patients with cytogenetic abnormalities at diagnosis achieved a complete cytogenetic response at the end of 12 months of combination therapy. The combination was relatively well tolerated with only transient grade $3 / 4$ myelosuppression that did not warrant treatment interruption [55] (NCT01787487).

CPI-0610 is a novel Bromodomain and Extraterminal domain Protein (BET) inhibitor that is currently undergoing clinical evaluation with two treatment arms investigating the "add-on" approach with ruxolitinib in MF patients in the JAK inhibitor naïve $[\operatorname{Arm}(\mathrm{A}) 3]$ and experienced (A2) with suboptimal response settings and the other evaluating CPI-0610 monotherapy in patients after ruxolitinib discontinuation (A1). In the first-line setting (A3), 73\% achieved SVR35\% at 12 weeks; 59\% achieved TSS50, and 46\% experienced at least one-grade improvement in BMF. In the JAK inhibitor "experienced" cohort, patients were stratified by red blood cell transfusion status. While $34 \%$ of evaluable transfusion-dependent (TD) patients converted to TI in A2 (NCT02158858), 21\% of TD patients converted to TI in A1 and SVR35\% was comparable in A1 (24\%) and A2 (22\%). CPI-0610 was tolerable with minimal grade $3 / 4$ myelosuppression, and thrombocytopenia, low-grade nausea, and vomiting were the most commonly observed TEAE $[56,57]$. Given these encouraging results (spleen and symptom response) and the potential disease-modifying activity (improvement in anemia and bone marrow fibrosis), a phase III, doubleblind, randomized study comparing combination CPI0610 and ruxolitinib to ruxolitinib monotherapy will start in the fourth quarter of 2020 (MANIFEST-2).

Phosphatidylinositol 3-Kinase (PI3K) inhibitors are being evaluated in combination with ruxolitinib to improve upon the suboptimal response to ruxolitinib in MF patients. In a phase II study of combination umbralisib and ruxolitinib therapy in MF, 9\% (2/23) of treated patients achieved a complete response (CR), and $48 \%$
$(11 / 23)$ experienced clinical improvement. One patient experienced colitis, but other class-specific side effects (hepatotoxicity, pneumonitis) were not observed [58]. The recently presented interim study results of parsaclisib, a potent and highly selective next-generation $\mathrm{PI} 3 \mathrm{~K} \delta$ inhibitor in combination with ruxolitinib. Parsaclisib was evaluated in two dosing schedules (QD for eight weeks followed by weekly; daily). Recently presented data showed that the intensive daily dosing schedule was found to be more efficacious than the weekly schedule (median percent change in spleen volume: $-13 \%$ vs. $-2.3 \%$; TSS: $-51.4 \%$ vs. $-14.0 \%$, respectively, at week 12]. Parsaclisib was well tolerated with no TEAE inherent to PI3K inhibitors (pneumonitis, colitis, diarrhea). Daily parsaclisib "add-on" to ruxolitinib will be evaluated further in a planned phase 3 trial (NCT02718300) [59].

Navitoclax, a non-selective $\mathrm{Bcl} 2$ inhibitor, is being evaluated in combination with ruxolitinib to improve response in patients with MF. These patients were heavily pretreated ( $>3$ lines of prior therapy), and $50 \%$ of treated patients harbored high molecular risk mutations $(n=34)$. Thirty percent of evaluable patients achieved SVR35\%, $35 \%$ achieved TSS50, and $\geq 1$-grade BMF reduction was seen in $25 \%$ of patients suggesting disease-modifying activity. On target thrombocytopenia was the most common TEAE, but there were no grade $\geq 3$ bleeding events or treatment-related deaths. The combination was welltolerated, and this combination will be evaluated in randomized phase 3 trials in both treatment-naïve and JAK inhibitor-treated patients [60] (NCT03222609).

A phase I/II RUXOPEG adaptive design trial is evaluating the combination of ruxolitinib and pegylated interferon alfa-2a in treatment-naïve DIPSS intermediate- or high-risk MF patients on the basis that this combination may permit administration of lower doses of interferon and improve tolerability. Phase I will test different combinations of three dose levels of each drug, and phase II will randomize the two best dose combinations from the phase I. The primary endpoint is composed of safety and efficacy objectives as denoted by the dose-limiting toxicity (DLT) within 45 days and SVR50\% in 24 weeks, respectively. Thus far, fifteen patients have been enrolled in phase I; no DLT has been observed in the highest dose tested (ruxolitinib $15 \mathrm{mg}$ BID + IFNa $135 \mathrm{mcg} /$ week), and an early signal for efficacy has been reported (three-partial responses, seven-hematological improvement). The trial is ongoing (NCT02742324) [61].

\section{Second line: JAK inhibitor relapsed/ refractory/intolerant setting}

The 5-year follow-up of the COMFORT-1 trial reported a median duration of approximately 3.2 years of spleen 
response, suggesting that the disease response to JAK inhibitors is not everlasting [62]. Although progressive disease per IWG-MRT includes only new/progressive splenomegaly and increasing blast counts either in the blood or marrow, clinically patients may exhibit evidence of disease progression through worsening cytopenias or loss of symptom response [63]. Currently, the widely accepted definition of ruxolitinib failure is centered around spleen size and presence of cytopenias (Table 1) [52]. Furthermore, a retrospective claims database study reported that the median treatment progression-free survival after ruxolitinib discontinuation is six months, 95\% (CI: 4.4, 8.3 months), which, coupled with poor outcomes post discontinuation, reiterates the urgent need to explore novel therapeutic options in MF patients experiencing ruxolitinib failure (relapsed/ refractory or intolerant to ruxolitinib treatment) [64].

Momelotinib is a JAK1/2 inhibitor as well as a type 1 activin receptor (ACVR1) inhibitor being evaluated in MF patients with anemia on the premise that ACVR1 inhibition regulates hepcidin levels to restore iron homeostasis and improve anemia [66]. SIMPLIFY-1 study compared momelotinib with ruxolitinib in treatment-naïve MF patients. Although the trial met the non-inferiority primary endpoint for $\geq 35 \%$ SVR at 24 weeks (26.5\% for momelotinib versus $29 \%$ for ruxolitinib, $p=0.011$ ), it failed to meet the TSS50 endpoint. Notably, the momelotinib treatment arm enjoyed a higher rate of TI at week 24 than the ruxolitinib arm (66.5\% vs. $49.3 \%$, nominal $p<0.001)$ [67]. SIMPLIFY-2 compared momelotinib to BAT (including ruxolitinib) in MF patients intolerant to ruxolitinib. The study failed to meet its primary endpoint SVR35\%, but the TSS50 endpoint was met. Akin to SIMPLIFY-1, more momelotinib-treated patients achieved TI ( $43 \%$ vs. $21 \%$ nominal $p=0.0012$ ) [68]. However, in both trials, the hierarchal study design precluded the investigators from claiming the statistically significant anemia-related endpoints. Most recently, an open-label phase II study evaluated momelotinib in RBC TD patients with MF, and 34\% achieved TI at week 24 [69]. The MOMENTUM trial will compare momelotinib to danazol in symptomatic and anemic patients with MF in the second-line setting (NCT04173494).

PRM-151 is a recombinant form of pentraxin-2, an endogenous serum amyloid protein that downregulates activated fibrogenic monocyte-macrophages activity in several organ models of fibrosis, including the bone marrow [70]. The first stage of phase II, open-label, extension study showed that PRM-151 was well tolerated as a monthly infusion either alone or in combination with ruxolitinib, and no unexpected AEs were observed in patients with MF. TSS50 was similar between both arms, and $44 \%$ of treated patients experienced at least a 1-grade reduction from grade $3 \mathrm{BMF}$ at baseline (NCT01981850) [71]. In stage two, randomized, double-blind evaluation of three dose levels of PRM-151 infusional monotherapy in MF patients intolerant/refractory to JAK inhibitors, the primary endpoint was to determine the effective dose inducing at least a 1-grade reduction in BMF. All tested dose levels demonstrated greater than 1-grade BMF reduction, and the effect was similar across the tested doses $[0.3 \mathrm{mg} / \mathrm{kg}: 30 \%$; $3 \mathrm{mg} / \mathrm{kg}: 28 \%$, and $10 \mathrm{mg} /$ kg: 25\%]. SVR35\% was observed in only one patient. PRM-151 was well tolerated, and non-hematological AEs included fatigue, cough, and weight loss. Despite these encouraging findings, the further development of this drug in MF is uncertain as it evinced mostly BMF reduction. PRM-151 is currently undergoing registration trials in idiopathic pulmonary fibrosis [72].

Bomedemstat inhibits LSD1, an epigenetic target of interest in MPNs. LSD1 is essential for normal megakaryocyte function, and thrombocytopenia would be an expected dose-limiting side effect of LSD1 inhibition. In a phase II trial of bomedemstat in the second-line setting $(n=31), 12.5 \%$ of treated patients achieved SVR35\%, $44.4 \%$ experienced TSS50, and $\geq 1$-grade BMF reduction was noted in $15 \%$ of treated patients. Given the expectant thrombocytopenia, the dose up-titration of bomedemstat was individualized to achieve a target platelet count of $50 \times 10^{9} /$ L. No new safety signals or DLTs were observed. Further evaluation is underway (NCT03136185) [73].

Harnessing the targets in the apoptotic machinery has long been an object of clinical interest in MF. KRT-232,

Table 1 Criteria for ruxolitinib failure in patients with MF-adapted from $[52,65]$

\begin{tabular}{|c|c|c|c|}
\hline Criteria & Ruxolitinib duration & Cytopenias & Spleen size \\
\hline Relapsed & $\geq 3$ months & - & $\begin{array}{c}\text { Regrowth }<10 \% \text { SVR or }<30 \% \text { decrease in spleen size by } \\
\text { palpation from baseline following an initial response }\end{array}$ \\
\hline Refractory & $\geq 3$ months & - & $\begin{array}{l}<10 \% \text { SVR or }<30 \% \text { decrease in spleen size by palpation } \\
\text { from baseline }\end{array}$ \\
\hline Intolerant & $\geq 28$ days & $\begin{array}{l}\text { New grade } \geq 3 \text { thrombocytopenia, anemia, hematoma/ } \\
\text { hemorrhage or } \mathrm{RBC} \text { transfusion requirement } \geq 2 \\
\text { units/month for } 2 \text { months }\end{array}$ & - \\
\hline
\end{tabular}


a potent oral MDM2 inhibitor, is currently under clinical investigation in the second-line setting in patients with advanced MF. This study excludes patients who are intolerant to ruxolitinib and does not require a ruxolitinib washout period [74]. Patients were randomly assigned to either of the three-dose arms (120 (A1) or $240 \mathrm{mg}$ (A3) daily for seven days in a 21-day cycle or $240 \mathrm{mg}$ daily (A3) for seven days in a 28-day cycle). As $16 \%$ of patients achieved SVR35\% in A3, $240 \mathrm{mg}$ daily for seven days in a 28-day cycle is deemed to be the RP2D for further evaluation. In total, $51 \%$ of treated patients experienced grade 3 TEAE with gastrointestinal symptoms being the most common AEs [diarrhea (62\%) and nausea (38\%)] [75] (NCT03662126). KRT-232 is now being evaluated as combination therapy with ruxolitinib in a phase $1 / 2$ trial enrolling patients with suboptimal response to single agent ruxolitinib (NCT04485260).

LCL-161 is an oral second mitochondrial activator of caspases (SMAC) mimetic that inhibits apoptosis and is administered on a weekly basis. The phase 2 study included all comers with advanced MF in the second-line setting with no restrictions for platelet count or previous HCT. Among 47 evaluable patients, 32\% ORR was observed with most response improvement in symptom burden and anemia; only one patient had a spleen response. Fatigue was the most common cause for dose reduction, and low-grade nausea/vomiting was observed in $60 \%$ of the patients [76] (NCT02098161).

Alisertib is an aurora kinase A (AURKA) inhibitor that promotes megakaryocyte differentiation in MF and may mitigate bone marrow fibrosis. Alisertib was evaluated in patients with advanced MF in the second-line setting with a minimum platelet count $\geq 50 \times 10^{9} / \mathrm{L}$ and absolute neutrophil count $\geq 1 \times 10^{9} / \mathrm{L}$. Alisertib was well tolerated, and spleen and symptom improvement were observed in $29 \%$ and $32 \%$ of patients, respectively. Most importantly, alisertib normalized the atypical morphology of megakaryocytes (restored the multilobed nuclei and abrogated clustering), and among the seven patients with available sequential marrow samples, five patients experienced $>1$-grade BMF, which correlated with the clinical responses (NCT02530619). The future development pathway for Alisertib is unclear [77].

Tagraxofusp is a CD123-targeted agent and currently approved in the treatment of blastic plasmacytoid dendritic cell neoplasm [78]. The shared phylogeny of plasmacytoid dendritic cells and monocytes, coupled with poor outcomes in MF patients with peripheral blood monocytosis, prompted the evaluation of tagraxofusp in the second-line setting. The study included all comers with no limitation in minimal platelet count at enrollment, and $26 \%$ of patients had documented monocytosis at baseline. Tagraxofusp was administered intravenously for three consecutive days in a 28-day cycle. Among 20 evaluable patients, $35 \%$ experienced objective clinical improvement, and 53\% with baseline splenomegaly had some degree of reduction in spleen size as their best response. Tagraxofusp was reasonably well tolerated, with one patient experiencing grade 3 capillary leak syndrome [79] (NCT02268253).

Imetelstat is a competitive inhibitor of the telomerase enzyme complex comprising the RNA template with reverse transcriptase activity (hTERT). In a proof of concept study of 33 patients with advanced MF, imetelstat evinced an ORR of $21 \%$ limited to those with $J A K 2$, $S F 3 B 1$, or $U 2 A F 1$ mutations. The study did not show ontarget activity (telomerase length) [80]. The subsequent phase 2, global IMBARK trial evaluated two dose levels of imetelstat $(4.7 \mathrm{mg} / \mathrm{kg}$ and $9.4 \mathrm{mg} / \mathrm{kg})$ administered intravenously every three weeks in 107 patients with advanced MF in the second-line setting (NCT02426086). Although SVR35\% (10\%) and TSS50 (32\%) were only modest in the higher dose arm, the median survival was 29.9 months as compared with 19 months in the low-dose arm and the reported median survival of 13-14 months following ruxolitinib discontinuation [81]. Furthermore, imetelstat exhibited on-target activity and brought about greater than 50\% reduction of hTERT expression levels, which correlated with clinical responses and longer OS in the $9.4 \mathrm{mg} / \mathrm{kg}$ arm [82]. Most importantly, the survival advantage of imetelstat was validated in a real-world cohort using a closely matched propensity score analysis [ $30.69 \mathrm{mo}$ ( $95 \%$ CI 25.2 , not estimable) vs. $12.04 \mathrm{mo}$ (95\% CI 9.5, 16.6) (BAT)] [83]. Given these encouraging results, the phase III registration trial of imetelstat is soon underway with OS as the primary endpoint, a novel endpoint that has never been explored in the drug development landscape of MF.

\section{Drugs targeting cytopenias in MF}

Anemia independently predicts shortened survival in MF, and TD-anemia categorizes an MF patient in the higherrisk category regardless of the presence or absence of other adverse risk factors [84]. Furthermore, anemia is the most common reason for ruxolitinib discontinuation [49]. Several drugs are in clinical development for mitigating anemia in MF so as to safely continue MF-directed therapy. MPNSG-0212, a German study, evaluated pomalidomide in combination with ruxolitinib [two dose levels of pomalidomide: fixed low dose (A1) and dose escalation up to $2 \mathrm{mg}$ (A2)] in MF patients with anemia \pm RBC-TD. The A1 cohort exhibited an ORR of $18 \%$, and there was a trend to sustained hemoglobin improvement with longer durations of treatment. TEAE was comparable between both arms with pneumonia and sepsis being the most grade $\geq 3$ AEs [85]. 
Table 2 Agents currently in early phase of clinical development in myelofibrosis

\begin{tabular}{|c|c|c|c|c|c|c|}
\hline Drug & $\begin{array}{l}\text { Mechanism } \\
\text { of action }\end{array}$ & Setting & End points & Status & NCT id & References \\
\hline PIM447 and LEE011 & $\begin{array}{l}\text { pan-PIM inhibi- } \\
\text { tor, and CDK4/6 } \\
\text { inhibitor }\end{array}$ & $\begin{array}{l}\text { Add on to ruxolitinib } \\
\text { phase } 1 b\end{array}$ & Incidence of DLTS & A & NCT02370706 & {$[93]$} \\
\hline Enasidenib & IDH2 inhibitor & Add on phase 2 & $\begin{array}{l}2^{0} \text { _- Proportion of } \\
\text { patients with any } \\
\text { response }\end{array}$ & NYR & NCT04281498 & {$[94]$} \\
\hline APG-1252 & $\begin{array}{l}\text { parenteral } \mathrm{BH} 3 \\
\text { mimetic }\end{array}$ & Add on phase $1 \mathrm{~b} / 2$ & $\begin{array}{l}\text { DLT at each dose } \\
\text { level; SVR35\% or } \\
\text { TSS50 }\end{array}$ & NYR & NCT04354727 & - \\
\hline PU-H71 & $\begin{array}{l}\text { Epichaperome- } \\
\text { specific Hsp90 } \\
\text { inhibitor }\end{array}$ & Add on phase $1 \mathrm{~b}$ & - & $\begin{array}{l}\text { Terminated as of } \\
10 / 22 / 20\end{array}$ & NCT03373877 & {$[95]$} \\
\hline 1. Siremadlin & $\begin{array}{l}\text { 1. Inhibits p53-MDM2 } \\
\text { interaction }\end{array}$ & $\begin{array}{l}\text { Add on phase } 1 \\
\text { parallel design }\end{array}$ & \multirow{3}{*}{$\begin{array}{l}\text { Incidence DLT within } \\
\text { the first } 2 \text { cycles; } \\
\text { response at the } \\
\text { end of } 6 \text { cycles- } \\
\text { composite of ane- } \\
\text { mia improvement } \\
\text { and no spleen vol- } \\
\text { ume progression } \\
\text { and no symptom } \\
\text { worsening }\end{array}$} & \multirow[t]{3}{*}{$\mathrm{R}$} & \multirow{3}{*}{$\begin{array}{l}\text { NCT04097821 } \\
\text { (ADORE trial_- } \\
\text { platform design) }\end{array}$} & \multirow[t]{3}{*}{-} \\
\hline 2. Crizanlizumab & $\begin{array}{l}\text { 2. P-selectin mono- } \\
\text { clonal antibody }\end{array}$ & & & & & \\
\hline 3. MBG453 & $\begin{array}{l}\text { 3. humanized } \\
\text { anti-TIM-3 lgG4 } \\
\text { antibody }\end{array}$ & & & & & \\
\hline $9-\mid N G-41$ & $\begin{array}{l}\text { Glycogen Synthase } \\
\text { Kinase-3 inhibitor }\end{array}$ & Add on phase 2 & $\begin{array}{l}\% \text { of patients with } \\
\text { response accord- } \\
\text { ing to the Revised } \\
\text { IWG-MRT and ELN } \\
\text { Response Criteria } \\
\text { for MF (2013) }\end{array}$ & $\mathrm{R}$ & NCT04218071 & {$[96]$} \\
\hline Selinexor & $\begin{array}{l}\text { nuclear-cytoplasmic } \\
\text { transport inhibitor }\end{array}$ & Second line & $\begin{array}{l}\text { Change in spleen } \\
\text { volume within } \\
6 \text { months }\end{array}$ & $\mathrm{R}$ & NCT03627403 & {$[97]$} \\
\hline Pevonedistat & $\begin{array}{l}\text { NEDD8 activating } \\
\text { enzyme inhibitor }\end{array}$ & Add on & $\begin{array}{l}\text { Safety and tolerabil- } \\
\text { ity of the combina- } \\
\text { tion as measured } \\
\text { by the incidence of } \\
\text { AEs and MTD }\end{array}$ & $\mathrm{R}$ & NCT03386214 & {$[98]$} \\
\hline $\begin{array}{l}\text { Pembrolizumab } \\
\text { Nivolumab }\end{array}$ & $\begin{array}{l}\text { PD-1 pathway inhibi- } \\
\text { tors }\end{array}$ & Second line & $\begin{array}{l}\text { Response per ELN- } \\
\text { IWG criteria }\end{array}$ & $\begin{array}{l}\text { Completed Termi- } \\
\text { nate }\end{array}$ & $\begin{array}{l}\text { NCT03065400 } \\
\text { NCT02421354 }\end{array}$ & [99] \\
\hline AVID200 & $\begin{array}{l}\text { Selective TGF } \beta 1 \\
\text { ligand trap }\end{array}$ & Second line Phase 1 & $\begin{array}{l}\text { MTD and number } \\
\text { of patients with } \\
\text { response eligibility } \\
\text { for Phase } 1 \mathrm{~b}\end{array}$ & $\mathrm{R}$ & NCT03895112 & {$[100]$} \\
\hline ONC201 & $\begin{array}{l}\text { p53 independ- } \\
\text { ent promoter of } \\
\text { apoptosis }\end{array}$ & Second-line phase 1 & - & - & TBD & {$[101]$} \\
\hline TP3654 & $\begin{array}{l}\text { second-generation } \\
\text { pan-PIM kinase } \\
\text { inhibitor }\end{array}$ & Second-line phase 1 & $\begin{array}{l}\text { Determine the } \\
\text { incidence of DLT } \\
\text { and AE }\end{array}$ & $\mathrm{R}$ & NCT04176198 & {$[102]$} \\
\hline
\end{tabular}

PIM-Proviral Integration Site for Moloney Murine Leukemia Virus; CDK-Cyclin-Dependent Kinase; IDH—isocitrate dehydrogenase; BH3-B-cell lymphoma 2 (Bcl-2) homology 3; Hsp-heat-shock protein; MDM-murine double minute; TIM-T-cell immunoglobulin and mucin domain; NEDD-Neural precursor cell-Expressed Developmentally Downregulated genes; PD—programmed cell death protein; TGF-transforming growth factor; DLT-dose-limiting toxicity; A-active; NYR-not yet recruiting; R-recruiting; *-in MF pts; SVR35\%-35\% reduction in spleen volume within 24 weeks; TSS50- $\geq 50 \%$ reduction in myelofibrosis-related total symptom score within 24 weeks; AE-adverse events; MTD—maximum tolerated dose

Sotatercept and luspatercept are erythroid maturation agents (EMA) that act as activin receptor ligand traps of IIA and IIB, respectively [86, 87]. They are administered subcutaneously every three weeks, and luspatercept is currently approved for the treatment of anemia in low-risk myelodysplastic syndrome with ringed sideroblasts [88]. Sustained hemoglobin increase $\geq 1.5 \mathrm{~g} / \mathrm{dL}$ for $\geq 12$ consecutive weeks in TI patients or achieving $\mathrm{RBC}-\mathrm{TI}$ in TD patients is the primary endpoints in the clinical trial evaluation of these EMAs in MF. Sotatercept 
monotherapy demonstrated an ORR of 35\%, of which three patients achieved RBC-TI [89] (NCT01712308). In the recently presented study of luspatercept monotherapy and combination therapy with ruxolitinib in anemic patients with MF, $10 \%$ of treated patients each in the luspatercept monotherapy arm and $21 \%$ and $32 \%$ in the combination therapy arm achieved the primary endpoint in TI and TD patients, respectively (NCT03194542) [90]. Hypertension and bone pain were the most common, class-specific TEAE shared by both drugs. Further evaluation is ongoing, and a phase 3 trial is being planned.

Disease-related thrombocytopenia is an adverse prognostic factor in MF, which often precludes these patients from treatment with a JAK inhibitor or leads to dose attenuation resulting in suboptimal responses. Thalidomide in combination with prednisone has evoked modest improvement in platelet counts in patients with MF [91]. Most recently, a study of low-dose thalidomide in combination with ruxolitinib in patients with MF in the second-line setting (relapsed/refractory) showed an ORR of $60 \%$, and platelet response was observed in $75 \%$ of patients with baseline thrombocytopenia. The combination was well tolerated with one patient each experiencing a thromboembolic event and grade 3 neutropenia. This combination may allow for optimal dosing of ruxolitinib in MF patients with baseline thrombocytopenia [92].

Several other agents exploiting the interconnected pathological pathways in MF are in various stages of early-phase clinical development (Table 2).

\section{Conclusion}

Advances in diagnostic techniques, i.e., next-generation sequencing, single-cell transcriptome approaches, have carefully refined the molecular signature of MPNs, leading to enhanced insight on clonal dynamics and architecture, thereby informing rationally based treatment approaches. Although $\mathrm{HU}$ or IFNa is the frontline agent in the treatment of PV, $25 \%$ of patients are intolerant to these agents and experience disease progression while receiving therapy. In light of this, ongoing translational research endeavors have identified mechanistic-based targeted therapeutic agents that may improve the outcomes in PV. Comparably in MF, sustained disease-modifying activity or durable remissions are not seen with the currently approved JAK inhibitors, i.e., ruxolitinib and fedratinib. Therefore, it is crucial to improve upon the existing understanding of the disease and treatment-resistant mechanisms in MF. As such, research efforts are ongoing to develop novel JAK inhibitors or drugs with distinct mechanisms of action that offer a better side effect profile and tolerability in patients with MPNs. Ropeginterferon in lowrisk $\mathrm{PV}$, pacritinib in the front-line setting of extreme thrombocytopenia, CPI-0610 combination therapy in JAK inhibitor-naïve patients, imetelstat in the secondline setting to improve survival outcomes, and luspatercept for the treatment of MF patients with anemia are some of the promising agents that look to achieve results in phase 3 trials and gain regulatory approval for the treatment of MPNs.

\section{Abbreviations \\ JAK: Janus-associated kinase; STAT: Signal transducers and activators of tran- scription; MPN: Myeloproliferative neoplasms; PV: Polycythemia vera; ET: Essen- tial thrombocythemia; PMF: Primary myelofibrosis; USFDA: The United States Food and Drug Administration; HCT: Hematopoietic cell transplantation; HU: Hydroxyurea; IFNa: Pegylated interferon a; Ropeg: Ropeginterferon alfa-2b; MPD-RC: Myeloproliferative disorders research consortium; CHR: Complete hematological response; HDAC: Histone-deacetylase; TEAE: Treatment-related adverse event; LSD 1: Lysine-specific demethylase 1; TI: Transfusion independ- ence; TD: Transfusion dependence; SVR35\%: $\geq 35 \%$ Spleen volume reduction; IWG-MRT: International Working Group for Myelofibrosis Research and Treatment; BAT: Best available therapy; BMF: Bone marrow fibrosis; TSS50: $\geq$ 50\% Reduction in myelofibrosis-related total symptom score; A: Arm; BET: Bromodomain and Extraterminal domain Protein; PI3K: Phosphatidylinositol 3-Kinase; DLT: Dose-limiting toxicity; ACV: Activin receptor; SMAC: Second mitochondrial activator of caspases; AURKA: Aurora kinase A; TERT: RNA tem- plate with reverse transcriptase.}

\section{Acknowledgements}

None.

\section{Authors' contributions}

SV helped in conceptualization and writing - original manuscript preparation; $\mathrm{JM}$ helped in conceptualization, reviewing, and editing. Both authors read and approved the final manuscript.

Funding

None.

Availability of data and materials

Not applicable.

Ethics approval and consent to participate

Not applicable.

\section{Consent for publication}

Not applicable.

\section{Competing interests}

John Mascarenhas has received research funding paid to the institution from Incyte, Roche, CTI Biopharma, Novartis, Promedior, Merck, Janssen, Arog, Merus, and Pharma Essentia, Kartos, Forbius; consulting fees from Geron, Constellation, Prelude, Galecto, Promedior, and Celgene/BMS, Kartos. Sangeetha Venugopal has nothing to disclose.

\section{Author details \\ 1 Department of Leukemia, MD Anderson Cancer Center, University of Texas, Houston, TX, 77030, USA. ${ }^{2}$ Division of Hematology/Oncology, Tisch Cancer Institute, Icahn School of Medicine at Mount Sinai, One Gustave L Levy Place, Box 1079, New York, NY 10029, USA.}

Received: 14 October 2020 Accepted: 9 November 2020 Published online: 02 December 2020 


\section{References:}

1. Spivak JL. Myeloproliferative neoplasms. N Engl J Med. 2017;376(22):2168-81

2. Levine RL, Wadleigh M, Cools J, Ebert BL, Wernig G, Huntly BJ, et al. Activating mutation in the tyrosine kinase JAK2 in polycythemia vera, essential thrombocythemia, and myeloid metaplasia with myelofibrosis. Cancer Cell. 2005;7(4):387-97.

3. Nangalia J, Massie CE, Baxter EJ, Nice FL, Gundem G, Wedge DC, et al. Somatic CALR mutations in myeloproliferative neoplasms with nonmutated JAK2. N Engl J Med. 2013;369(25):2391-405.

4. Pikman Y, Lee BH, Mercher T, McDowell E, Ebert BL, Gozo M, et al. MPLW515L is a novel somatic activating mutation in myelofibrosis with myeloid metaplasia. PLoS Med. 2006;3(7):e270.

5. Mascarenhas J, Roper N, Chaurasia P, Hoffman R. Epigenetic abnormalities in myeloproliferative neoplasms: a target for novel therapeutic strategies. Clinical epigenetics. 2011;2(2):197-212. https://doi. org/10.1007/s13148-011-0050-6.

6. Policitemia GIS. Polycythemia vera: the natural history of 1213 patients followed for 20 years. Ann Intern Med. 1995;123(9):656-64.

7. De Stefano V, Za T, Rossi E, Vannucchi AM, Ruggeri M, Elli E, et al. Recurrent thrombosis in patients with polycythemia vera and essential thrombocythemia: incidence, risk factors, and effect of treatments. Haematologica. 2008;93(3):372-80.

8. Hultcrantz M, Andersson TM, Landgren O, Derolf AR, Dickman PW, Björkholm M, et al. Risk of arterial and venous thrombosis in 11,155 patients with myeloproliferative neoplasms and 44,620 matched controls; a population-based study. Washington, DC: American Society of Hematology; 2014.

9. Kennedy JA, Atenafu EG, Messner HA, Craddock KJ, Brandwein JM Lipton JH, et al. Treatment outcomes following leukemic transformation in Philadelphia-negative myeloproliferative neoplasms. Blood J Am Soc Hematol. 2013;121(14):2725-33.

10. Tefferi A, Rumi E, Finazzi G, Gisslinger H, Vannucchi A, Rodeghiero F, et al. Survival and prognosis among 1545 patients with contemporary polycythemia vera: an international study. Leukemia. 2013;27(9):1874-81

11. Barbui T, Finazzi G, Carobbio A, Thiele J, Passamonti F, Rumi E, et al. Development and validation of an International Prognostic Score of thrombosis in World Health Organization-essential thrombocythemia (IPSET-thrombosis). Blood. 2012;120(26):5128-33.

12. Ali H, Aldoss I, Yang D, Mokhtari S, Khaled S, Aribi A, et al. MIPSS70+ v2.0 predicts long-term survival in myelofibrosis after allogeneic HCT with the Flu/Mel conditioning regimen. Blood Adv. 2019;3(1):83-95.

13. Barbui T, Carobbio A, Rumi E, Finazzi G, Gisslinger H, Rodeghiero F, et al. In contemporary patients with polycythemia vera, rates of thrombosis and risk factors delineate a new clinical epidemiology. Blood J Am Soc Hematol. 2014;124(19):3021-3.

14. Marchioli R, Finazzi G, Specchia G, Cacciola R, Cavazzina R, Cilloni D, et al. Cardiovascular events and intensity of treatment in polycythemia vera. N Engl J Med. 2013;368(1):22-33.

15. Patrono C, Rocca B, De Stefano V. Platelet activation and inhibition in polycythemia vera and essential thrombocythemia. Blood. 2013;121(10):1701-11.

16. Fruchtman SM, Mack K, Kaplan ME, Peterson P, Berk PD, Wasserman LR. From efficacy to safety: a Polycythemia Vera Study group report on hydroxyurea in patients with polycythemia vera. Semin Hematol. 1997;34(1):17-23.

17. Cortelazzo S, Finazzi G, Ruggeri M, Vestri O, Galli M, Rodeghiero F, et al. Hydroxyurea for patients with essential thrombocythemia and a high risk of thrombosis. N Engl J Med. 1995;332(17):1132-6.

18. Kiladjian JJ, Cassinat B, Chevret S, Turlure P, Cambier N, Roussel M, et al. Pegylated interferon-alfa-2a induces complete hematologic and molecular responses with low toxicity in polycythemia vera. Blood. 2008;112(8):3065-72.

19. Verger E, Cassinat B, Chauveau A, Dosquet C, Giraudier S, Schlageter $\mathrm{M}-\mathrm{H}$, et al. Clinical and molecular response to interferon-a therapy in essential thrombocythemia patients with CALR mutations. Blood J Am Soc Hematol. 2015;126(24):2585-91.

20. Vannucchi AM, Kiladjian JJ, Griesshammer M, Masszi T, Durrant S, Passamonti F, et al. Ruxolitinib versus standard therapy for the treatment of polycythemia vera. N Engl J Med. 2015;372(5):426-35
21. Passamonti F, Griesshammer M, Palandri F, Egyed M, Benevolo G, Devos $\mathrm{T}$, et al. Ruxolitinib for the treatment of inadequately controlled polycythaemia vera without splenomegaly (RESPONSE-2): a randomised, open-label, phase 3b study. Lancet Oncol. 2017;18(1):88-99.

22. Casu C, Oikonomidou PR, Chen H, Nandi V, Ginzburg Y, Prasad P, et al. Minihepcidin peptides as disease modifiers in mice affected by betathalassemia and polycythemia vera. Blood. 2016;128(2):265-76.

23. King KY, Matatall KA, Shen C-C, Goodell MA, Swierczek SI, Prchal $J T$. Comparative long-term effects of interferon a and hydroxyurea on human hematopoietic progenitor cells. Exp Hematol. 2015;43(10):912-8.

24. Kiladjian J-J, Cassinat B, Turlure P, Cambier N, Roussel M, Bellucci S, et al. High molecular response rate of polycythemia vera patients treated with pegylated interferon a-2a. Blood. 2006;108(6):2037-40.

25. Quintás-Cardama A, Kantarjian H, Manshouri T, Luthra R, Estrov Z, Pierce $S$, et al. Pegylated interferon alfa-2a yields high rates of hematologic and molecular response in patients with advanced essential thrombocythemia and polycythemia vera. J Clin Oncol. 2009;27(32):5418.

26. Yacoub A, Mascarenhas J, Kosiorek H, Prchal JT, Berenzon D, Baer MR, et al. Pegylated interferon alfa-2a for polycythemia vera or essential thrombocythemia resistant or intolerant to hydroxyurea. Blood. 2019;134(18):1498-509.

27. Them NC, Bagienski K, Berg T, Gisslinger B, Schalling M, Chen D, et al. Molecular responses and chromosomal aberrations in patients with polycythemia vera treated with peg-proline-interferon alpha-2b. Am J Hematol. 2015;90(4):288-94.

28. Gisslinger $H$, Zagrijtschuk O, Buxhofer-Ausch V, Thaler J, Schloegl E, Gastl GA, et al. Ropeginterferon alfa-2b, a novel IFNa-2b, induces high response rates with low toxicity in patients with polycythemia vera. Blood J Am Soc Hematol. 2015;126(15):1762-9.

29. Tiziano Barbui AMV, Valerio De Stefano, Arianna M, Alessandra C, Arianna G, Fabio C, Massimiliano B, Alessandra I, Francesca P, Giulia B, Fabrizio P, Alessandra R, Giuseppe C, Marianna C, Davide R, Caterina M, Sergio S, Elisa R, Andrea P, Nicola C, Barbara M, Emma C, Giuseppe GL, Paola G, Elena R, Silvia B, Francesca L, Luigi S, Cristina B, Nicola V, Marta B, Alessandro R. Phase II Randomized clinical trial comparing ropeginterferon versus phlebotomy in low-risk patients with polycythemia Vera. Results of the Pre-planned Interim Analysis. EHA. EHA Library. Barbui T. 06/14/20; 303391; LB26022020.

30. Mascarenhas J, Kosiorek HE, Prchal JT, Rambaldi A, Berenzon D, Yacoub A, et al. Results of the myeloproliferative neoplasms-research consortium (MPN-RC) 112 randomized trial of pegylated interferon alfa-2a (PEG) versus hydroxyurea (HU) therapy for the treatment of high risk polycythemia vera (PV) and high risk essential thrombocythemia (ET). Blood. 2018;132(Supplement 1):577.

31. Gisslinger H, Klade C, Georgiev P, Krochmalczyk D, Gercheva-Kyuchukova L, Egyed M, et al. Ropeginterferon alfa-2b versus standard therapy for polycythaemia vera (PROUD-PV and CONTINUATION-PV): a randomised, non-inferiority, phase 3 trial and its extension study. Lancet Haematol. 2020;7(3):e196-208.

32. Guerini V, Barbui V, Spinelli O, Salvi A, Dellacasa C, Carobbio A, et al. The histone deacetylase inhibitor ITF2357 selectively targets cells bearing mutated JAK2V617F. Leukemia. 2008:22(4):740-7.

33. Rambaldi A, Dellacasa CM, Finazzi G, Carobbio A, Ferrari ML, Guglielmelli $P$, et al. A pilot study of the Histone-Deacetylase inhibitor Givinostat in patients with JAK2V617F positive chronic myeloproliferative neoplasms. Br J Haematol. 2010;150(4):446-55.

34. Finazzi G, Vannucchi AM, Martinelli V, Ruggeri M, Nobile F, Specchia G, et al. A phase II study of Givinostat in combination with hydroxycarbamide in patients with polycythaemia vera unresponsive to hydroxycarbamide monotherapy. Br J Haematol. 2013;161(5):688-94.

35. Rambaldi A, lurlo A, Vannucchi AM, Noble R, von Bubnoff N, Guarini A, et al. Safety and efficacy of the maximum tolerated dose of givinostat in polycythemia vera: a two-part Phase lb/II study. Leukemia. 2020;34(8):2234-7.

36. Lu M, Xia L, Li Y, Wang X, Hoffman R. The orally bioavailable MDM2 antagonist RG7112 and pegylated interferon a 2a target JAK2V617Fpositive progenitor and stem cells. Blood. 2014;124(5):771-9.

37. Mascarenhas J, Lu M, Kosiorek H, Virtgaym E, Xia L, Sandy L, et al. Oral idasanutlin in patients with polycythemia vera. Blood J Am Soc Hematol. 2019;134(6):525-33. 
38. Niebel D, Kirfel J, Janzen V, Höller T, Majores M, Gütgemann I. Lysinespecific demethylase 1 (LSD1) in hematopoietic and lymphoid neoplasms. Blood. 2014;124(1):151-2.

39. Jutzi JS, Kleppe M, Dias J, Staehle HF, Shank K, Teruya-Feldstein J, et al. LSD1 inhibition prolongs survival in mouse models of MPN by selectively targeting the disease clone. HemaSphere. 2018;2(3):e54.

40. Theocharides AP, Lundberg P, Lakkaraju AK, Lysenko V, Myburgh R, Aguzzi A, et al. Homozygous calreticulin mutations in patients with myelofibrosis lead to acquired myeloperoxidase deficiency. Blood J Am Soc Hematol. 2016;127(25):3253-9.

41. Elf S, Abdelfattah NS, Chen E, Perales-Patón J, Rosen EA, Ko A, et al. Mutant calreticulin requires both its mutant $C$-terminus and the thrombopoietin receptor for oncogenic transformation. Cancer Discov. 2016;6(4):368-81.

42. Holmström MO, Ahmad SM, Klausen U, Bendtsen SK, Martinenaite E, Riley $\mathrm{CH}$, et al. High frequencies of circulating memory $T$ cells specific for calreticulin exon 9 mutations in healthy individuals. Blood Cancer J. 2019:9(2):1-14

43. Holmström M, Martinenaite E, Ahmad S, Met Ö, Friese C, Kjaer L, et al. The calreticulin (CALR) exon 9 mutations are promising targets for cancer immune therapy. Leukemia. 2018;32(2):429-37.

44. Cimen Bozkus C, Roudko V, Finnigan JP, Mascarenhas J, Hoffman $\mathrm{R}$, lancu-Rubin C, et al. Immune Checkpoint Blockade Enhances Shared Neoantigen-Induced T-cell Immunity Directed against Mutated Calreticulin in Myeloproliferative Neoplasms. Cancer Discov. 2019;9(9):1192-207

45. Verstovsek S, Mesa RA, Gotlib J, Levy RS, Gupta V, DiPersio JF, et al. A double-blind, placebo-controlled trial of ruxolitinib for myelofibrosis. $N$ Engl J Med. 2012;366(9):799-807.

46. Harrison CN, Schaap N, Vannucchi AM, Kiladjian JJ, Tiu RV, Zachee P, et al. Janus kinase-2 inhibitor fedratinib in patients with myelofibrosis previously treated with ruxolitinib (JAKARTA-2): a single-arm, openlabel, non-randomised, phase 2, multicentre study. Lancet Haematol. 2017;4(7):e317-24.

47. Newberry KJ, Patel K, Masarova L, Luthra R, Manshouri T, Jabbour E, et al. Clonal evolution and outcomes in myelofibrosis after ruxolitinib discontinuation. Blood J Am Soc Hematol. 2017;130(9):1125-31.

48. Verstovsek S, Gotlib J, Mesa RA, Vannucchi AM, Kiladjian J-J, Cervantes $F$, et al. Long-term survival in patients treated with ruxolitinib for myelofibrosis: COMFORT-I and -II pooled analyses. J Hematol Oncol. 2017;10(1):156.

49. Kuykendall AT, Shah S, Talati C, Al Ali N, Sweet K, Padron E, et al. Between a rux and a hard place: evaluating salvage treatment and outcomes in myelofibrosis after ruxolitinib discontinuation. Ann Hematol. 2018;97(3):435-41.

50. Mesa RA, Vannucchi AM, Mead A, Egyed M, Szoke A, Suvorov A, et al Pacritinib versus best available therapy for the treatment of myelofibrosis irrespective of baseline cytopenias (PERSIST-1): an international, randomised, phase 3 trial. Lancet Haematol. 2017:4(5):e225-36.

51. Mascarenhas J, Hoffman R, Talpaz M, et al. Pacritinib vs. best available therapy, including ruxolitinib, in patients with myelofibrosis: a randomized clinical trial. JAMA Oncol. 2018;4(5):652-9.

52. Gerds AT, Savona MR, Scott BL, Talpaz M, Egyed M, Harrison CN, et al. Results of PAC203: a randomized phase 2 dose-finding study and determination of the recommended dose of pacritinib. Blood. 2019;134(1):667.

53. Harrison CN, Gerds AT, Kiladjian J-J, Döhner K, Buckley SA, Smith JA, et al. Pacifica: a randomized, controlled phase 3 study of pacritinib vs. Physician's choice in patients with primary myelofibrosis, post polycythemia vera myelofibrosis, or post essential thrombocytopenia myelofibrosis with severe thrombocytopenia (platelet count $<50,000$ / mL). Blood 2019;134(Supplement_1):4175.

54. Mascarenhas JO, Talpaz M, Gupta V. Foltz LM, Savona MR, Paquette R, et al. Primary analysis of a phase II open-label trial of INCB039110, a selective JAK1 inhibitor, in patients with myelofibrosis. Haematologica. 2017;102(2):327-35.

55. Masarova L, Verstovsek S, Hidalgo-Lopez JE, Pemmaraju N, Bose P, Estrov $Z$, et al. A phase 2 study of ruxolitinib in combination with azacitidine in patients with myelofibrosis. Blood. 2018;132(16):1664-74.

56. Mascarenhas J, Ch AP, Td FPRR, et al. CPI-0610, a bromodomain and extraterminal domain protein (BET) inhibitor, in combination with ruxolitinib. In JAK inhibitor treatment naïve myelofibrosis patients: update from manifest phase 2 study. EHA25; Virtual2020.

57. Verstovsek S, JM, MK, RH, RR, VG, et al. CPI-0610, Bromodomain and extraterminal domain protein (BET) inhibitor, as 'add-on' to ruxolitinib (RUX). In: Advanced myelofibrosis patients with suboptimal response: update of manifest phase 2 study. EHA25; Virtual2020.

58. Moyo T, JP, YH, OO, SM, RC, et al. Resurrecting response to ruxolitinib: a phase I study testing the combination of ruxolitinib and the PI3K delta inhibitor umbralisib in ruxolitinib-experienced myelofibrosis. EHA2018.

59. Yacoub A, ESW, RKR, UB, MK, HA, et al. Addition of parsaclisib, a PI3KDELTA inhibitor. In: Patients (PTS) with suboptimal response to ruxolitinib (RUX): a phase 2 study in PTS with myelofibrosis (MF). EHA 6/12/202020.

60. Harrison CN, Garcia JS, Mesa RA, Somervaille TC, Komrokji RS, Pemmaraju N, et al. Results from a phase 2 study of navitoclax in combination with ruxolitinib in patients with primary or secondary myelofibrosis. Blood. 2019;134(Supplement_1):671.

61. Kiladjian J-J, Soret-Dulphy J, Resche-Rigon M, Boyer-Perrard F, Barraco F, Rolland-Neyret $V$, et al. Ruxopeg, a multi-center bayesian phase 1/2 adaptive randomized trial of the combination of ruxolitinib and pegylated interferon alpha $2 \mathrm{a}$ in patients with myeloproliferative neoplasm (MPN)-associated myelofibrosis. Blood. 2018;132(Supplement_1):581.

62. Verstovsek S, Mesa RA, Gotlib J, Gupta V, DiPersio JF, Catalano JV, et al. Long-term treatment with ruxolitinib for patients with myelofibrosis: 5-year update from the randomized, double-blind, placebo-controlled, phase 3 COMFORT-I trial. J Hematol Oncol. 2017;10(1):55.

63. Tefferi A, Cervantes F, Mesa R, Passamonti F, Verstovsek S, Vannucchi AM, et al. Revised response criteria for myelofibrosis: International Working Group-Myeloproliferative Neoplasms Research and Treatment (IWG-MRT) and European LeukemiaNet (ELN) consensus report. Blood. 2013;122(8):1395-8.

64. Mascarenhas J, Mehra M, He J, Potluri R, Loefgren C. Patient characteristics and outcomes after ruxolitinib discontinuation in patients with myelofibrosis. J Med Econ. 2020;23(7):721-7.

65. Harrison CN, Schaap N, Vannucchi AM, Kiladjian J-J, Jourdan E, Silver RT, et al. Fedratinib in patients with myelofibrosis previously treated with ruxolitinib: an updated analysis of the JAKARTA2 study using stringent criteria for ruxolitinib failure. Am J Hematol. 2020;95(6):594-603.

66. Asshoff M, Petzer V, Warr MR, Haschka D, Tymoszuk P, Demetz E, et al. Momelotinib inhibits ACVR1/ALK2, decreases hepcidin production, and ameliorates anemia of chronic disease in rodents. Blood. 2017;129(13):1823-30.

67. Mesa RA, Kiladjian JJ, Catalano JV, Devos T, Egyed M, Hellmann A, et al. SIMPLIFY-1: a phase III randomized trial of momelotinib versus ruxolitinib in Janus kinase inhibitor-Naïve patients with myelofibrosis. J Clin Oncol. 2017;35(34):3844-50.

68. Harrison CN, Vannucchi AM, Platzbecker U, Cervantes F, Gupta V, Lavie $D$, et al. Momelotinib versus best available therapy in patients with myelofibrosis previously treated with ruxolitinib (SIMPLIFY 2): a randomised, open-label, phase 3 trial. Lancet Haematol. 2018;5(2):e73-81.

69. Oh ST, Talpaz M, Gerds AT, Gupta V, Verstovsek S, Mesa RA, et al. Hepcidin suppression by momelotinib is associated with increased iron availability and erythropoiesis in transfusion-dependent myelofibrosis patients. Blood. 2018;132(Supplement 1):4282.

70. Verstovsek S, Manshouri T, Pilling D, Bueso-Ramos CE, Newberry KJ, Prijic $S$, et al. Role of neoplastic monocyte-derived fibrocytes in primary myelofibrosis. J Exp Med. 2016;213(9):1723-40.

71. Verstovsek S, Hasserjian RP, Pozdnyakova O, Veletic I, Mesa RA, Foltz L, et al. PRM-151 in myelofibrosis: efficacy and safety in an open label extension study. Blood. 2018;132(Supplement 1):686.

72. Verstovsek S, MT, MW, JP, Al, PtB, et al. A randomized, double blind phase 2 study of 3 different doses of PRM-151 in patients with myelofibrosis who were previously treated with or ineligible for ruxolitinib. EHA242019.

73. Pettit K, Gerds AT, Yacoub A, Watts JM, Tartaczuch M, Bradley TJ, et al. A phase 2a study of the LSD1 inhibitor img-7289 (bomedemstat) for the treatment of myelofibrosis. Blood. 2019;134(Supplement_1):556.

74. Garcia-Delgado R, McLornan DP, Rejtő L, Jourdan E, Al-Ali HK, Pluta A, et al. An open-label, phase 2 study of KRT-232, a first-in-class, oral small molecule inhibitor of MDM2, for the treatment of patients with 
myelofibrosis ( $\mathrm{mf}$ ) who have previously received treatment with a JAK inhibitor. Blood. 2019;134(Supplement_1):2945.

75. Al-Ali HK, RGD, AL, AP, DPM, PV, et al. KRT-232, A first-in-class, murine double minute 2 inhibitor (MDM2I), for myelofibrosis (MF) relapsed or refractory (R/R) to Janus-associated kinase inhibitor (JAKI) Treatment (TX); 2020.

76. Pemmaraju N, Carter BZ, Kantarjian HM, Cortes JE, Bose P, Kadia TM, et al. Final results of phase 2 clinical trial of LCL161, a novel oral SMAC mimetic/IAP antagonist, for patients with intermediate to high risk myelofibrosis. Blood. 2019;134(Supplement_1):555.

77. Gangat N, Marinaccio C, Swords R, Watts JM, Gurbuxani S, Rademaker A, Fought AJ, Frankfurt O, Altman JK, Wen QJ, Farnoud N, Famulare CA, Patel A, Tapia R, Vallapureddy RR, Barath S, Graf A, Handlogten A, Zblewski D, Patnaik MM, Al-kali A, Dinh YT, Prahl KE, Patel S, Nobrega JC, Tejera D, Thomassen A, Gao J, Ji P, Rampal RK, Giles FJ, Tefferi A, Stein B, Crispino JD. Aurora kinase a inhibition provides clinical benefit, normalizes megakaryocytes, and reduces bone marrow fibrosis in patients with myelofibrosis: a phase I trial. Clin Cancer Res. 2019;25(16):4898-906.

78. Pemmaraju N, Lane AA, Sweet KL, Stein AS, Vasu S, Blum W, Rizzieri DA, Wang ES, Madeleine Duvic J, Sloan M, Spence S, Shemesh S, Brooks CL, Balser J, Bergstein I, Lancet JE, Kantarjian HM, Konopleva M. Tagraxofusp in blastic plasmacytoid dendritic-cell neoplasm. N Engl J Med. 2019;380(17):1628-37.

79. Pemmaraju N, Gupta V, Ali H, Yacoub A, Wang ES, Lee S, et al. Results from a phase $1 / 2$ clinical trial of tagraxofusp (SL-401) in patients with intermediate, or high risk, relapsed/refractory myelofibrosis. Blood. 2019;134(Supplement_1):558.

80. Cerquozzi S, Tefferi A. Blast transformation and fibrotic progression in polycythemia vera and essential thrombocythemia: a literature review of incidence and risk factors. Blood Cancer J. 2015;5:e366.

81. Mascarenhas J, Komrokji RS, Cavo M, Martino B, Niederwieser D, Reiter $A$, et al. Imetelstat Is effective treatment for patients with intermediate-2 or high-risk myelofibrosis who have relapsed on or are refractory to janus kinase inhibitor therapy: results of a phase 2 randomized study of two dose levels. Blood. 2018;132(Supplement_1):685.

82. Mascarenhas J, RSK, BM, DN, AR, BLS, et al. Telomerase activity, telomere length and htert expression correlate with clinical outcomes in higherrisk myelofibrosis (MF) relapsed/refractory (R/R) to Janus kinase inhibitor treated with Imetelstat; 2020.

83. Kuykendall A, Wan Y, Mascarenhas J, Kiladjian J-J, Vannucchi A, Wang J, et al. PS1456 favorable overall survival of imetelstat-treated relapsed/ refractory myelofibrosis patients compared with closely matched real world data. HemaSphere. 2019;3(S1):669-70.

84. Tefferi A. Anemia in myelofibrosis—prevalence, the U2AF1 connection, new treatments. Blood Cancer J. 2017;7(12):648.

85. Stegelmann F, Koschmieder S, Isfort S, Hochhaus A, Heidel F, Hebart H, et al. S1608 Ruxolitinib plus pomalidomide in myelofibrosis with Anemia: results from the MPNSG-0212 combination trial (NCT01644110). HemaSphere. 2019;3(S1):740-1.

86. Iancu-Rubin C, Mosoyan G, Wang J, Kraus T, Sung V, Hoffman R. Stromal cell-mediated inhibition of erythropoiesis can be attenuated by Sotatercept (ACE-011), an activin receptor type II ligand trap. Exp Hematol. 2013:41(2):155-66.

87. Carrancio S, Markovics J, Wong P, Leisten J, Castiglioni P, Groza MC, et al. An activin receptor II A ligand trap promotes erythropoiesis resulting in a rapid induction of red blood cells and haemoglobin. $\mathrm{Br} \mathrm{J}$ Haematol. 2014;165(6):870-82
88. Fenaux P, Platzbecker U, Mufti GJ, Garcia-Manero G, Buckstein R, Santini $\checkmark$, et al. Luspatercept in patients with lower-risk myelodysplastic syndromes. N Engl J Med. 2020;382(2):140-51.

89. Bose P, Daver N, Pemmaraju N, Jabbour EJ, Estrov Z, Pike A, et al. Sotatercept (ACE-011) alone and in combination with ruxolitinib in patients (pts) with myeloproliferative neoplasm (MPN)-associated myelofibrosis (MF) and anemia. Blood. 2017;130(Supplement_1):255.

90. Gerds AT, Vannucchi AM, Passamonti F, Kremyanskaya M, Gotlib JR, Palmer JM, et al. A phase 2 study of luspatercept in patients with myelofibrosis-associated anemia. Blood. 2019;134(Supplement_1):557.

91. Mesa RA, Steensma DP, Pardanani A, Li CY, Elliott M, Kaufmann SH, et al. A phase 2 trial of combination low-dose thalidomide and prednisone for the treatment of myelofibrosis with myeloid metaplasia. Blood. 2003;101(7):2534-41.

92. Rampal RK, Verstovsek S, Devlin SM, King AC, Stein EM, Pemmaraju N, et al. Safety and efficacy of combined ruxolitinib and thalidomide in patients with myelofibrosis: a phase II study. Blood. 2019;134(Supplement 1):4163.

93. Rampal RK, Maria P-O, Amritha Varshini HS, Levine RL, Cao A. Synergistic therapeutic efficacy of combined JAK1/2, Pan-PIM, and CDK4/6 inhibition in myeloproliferative neoplasms. Blood. 2016;128(22):634.

94. McKenney AS, Lau AN, Somasundara AVH, Spitzer B, Intlekofer AM, Ahn J, et al. JAK2/IDH-mutant-driven myeloproliferative neoplasm is sensitive to combined targeted inhibition. J Clin Invest. 2018;128(2):789-804.

95. Pemmaraju N, Gundabolu K, Pettit K, Talpaz M, Podoltsev NA, Schiller GJ et al. Phase $1 \mathrm{~b}$ study of the epichaperome inhibitor PU-H71 administered orally with ruxolitinib continuation for the treatment of patients with myelofibrosis. Blood. 2019;134(Supplement_1):4178.

96. Wu X, Stenson M, Abeykoon J, Nowakowski K, Zhang L, Lawson J, et al. Targeting glycogen synthase kinase 3 for therapeutic benefit in lymphoma. Blood. 2019;134(4):363-73.

97. Yan D, Pomicter AD, Tantravahi S, Mason CC, Senina AV, Ahmann JM, et al. Nuclear-cytoplasmic transport is a therapeutic target in myelofibrosis. Clin Cancer Res. 2019;25(7):2323-35.

98. Fisher DAC, Miner CA, Engle EK, Hu H, Collins TB, Zhou A, et al. Cytokine production in myelofibrosis exhibits differential responsiveness to JAKSTAT, MAP kinase, and NFKB signaling. Leukemia. 2019;33(8):1978-95.

99. Prestipino A, Emhardt AJ, Aumann K, O'Sullivan D, Gorantla SP, Duquesne S, et al. Oncogenic JAK2V617F causes PD-L1 expression, mediating immune escape in myeloproliferative neoplasms. Sci Transl Med. 2018;10(429):eaam7729.

100. Varricchio L, Mascarenhas J, Migliaccio AR, O'Connor-McCourt M, Tremblay G, Denis J-F, et al. AVID200, a potent trap for TGF- $\beta$ ligands inhibits TGF- $\beta 1$ signaling in human myelofibrosis. Blood. 2018;132(Supplement 1):1791.

101. Lu M, Xia L, Hoffman R. A novel combination of drugs which target both the intrinsic and extrinsic apoptotic pathways to eliminate myelofibrosis CD34+ cells. Blood. 2019;134(Supplement_1):4201.

102. Dutta A, Nath D, Yang Y, Mohi G. Abstract 1874: The PIM kinase inhibitor TP-3654 demonstrates efficacy in a murine model of myelofibrosis. Cancer Res. 2018;78(13 Supplement):1874.

\section{Publisher's Note}

Springer Nature remains neutral with regard to jurisdictional claims in published maps and institutional affiliations. 